\title{
Prevalence of Enteric Adenovirus among Non-Rotavirus Diarrhea in Assam, Northeast India
}

\author{
Biswajyoti Borkakoty ${ }^{1}$, Aniruddha Jakharia ${ }^{2}$, Chandrakanta Bhattacharya ${ }^{3}$, Mandakini Das ${ }^{4}$, \\ Dipankar Biswas ${ }^{5}$, Jagadish Mahanta ${ }^{6}$
}

\author{
${ }^{1}$ Scientist-D (M), ${ }^{2}$ Scientist-C (NM), ${ }^{3}$ Senior Research Fellow, ${ }^{4}$ Scientist-B (NM), \\ ${ }^{5}$ Scientist-E (NM), ${ }^{6}$ Distinguished Scientist Chair, \\ Regional Medical Research Centre for NE Region (ICMR), Dibrugarh, India.
}

\begin{abstract}
Introduction: Globally enteric adenovirus has become the second leading cause of viral diarrhea. Present investigation was undertaken to understand the adenoviral etiology of diarrhea among hospitalized children in Assam, northeast India.

Materials and methods: Over a period of two years (20132015), 455 faecal samples were collected from hospitalized children aged $<5$ years with diarrhea from Assam, northeast India for screening of rotavirus antigen. A total of 238 samples were rotavirus antigen negative and are screened for adenovirus antigen by ELISA and followed by PCR.

Results: Present investigation revealed enteric adenovirus infection in hospitalized children $<5$ years to be $10.9 \%$ (26/238). Prevalence was higher among infants (16.6\%) and females $(15.1 \%)$. Moreover, severe diarrhea ( $\geq 10$ times) $14.9 \% \quad(P=0.047)$ and restlessness $50 \% \quad(P=0.002) \quad$ is significantly higher in enteric adenovirus infected children. Enteric adenovirus infection was observed sporadically throughout the year; however infection was higher during warmer months (17\%) than cooler months $(7.3 \%)(P=0.0001)$. Adenovirus sequence analysis of the hexon gene showed adenovirus $F$ type- 41 to be the predominant serotype circulating in the study region. Analysis of the adenovirus fiber
\end{abstract}

\section{INTRODUCTION}

Diarrhea is the second leading cause of death among children below five years and accounts for approximately 2.6 million deaths worldwide. ${ }^{1}$ According to $\mathrm{WHO}$, over $70 \%$ of diarrheal related deaths among children occur in South Africa and South East Asia. ${ }^{1}$ Viruses are considered to be the major cause of acute diarrhea in young children. ${ }^{2}$ Four categories of viruses are considered to be important agents of viral diarrhea: group $A$ rotavirus (RVA), norovirus (NoV), adenovirus (AdV) and astrovirus (AstV). ${ }^{3}$ Among viral diarrhea, rotaviruse is considered to be the major etiological agent in causing children diarrhea. ${ }^{4}$ Human adenovirus (HAdV) detected worldwide in sporadic as well as in outbreaks cases of gastroenteritis and is considered to be second common agent of acute gastroenteritis (AGE). ${ }^{5-8}$

Adenovirus belongs to family Adenoviridae and genus Mastadenovirus. ${ }^{9}$ To date, there are 60 serotypes of adenovirus protein of the present study confirmed 15 amino acid deletions from the $15^{\text {th }}$ repeat motif of the shaft region.

Conclusions: Present data demonstrated that enteric adenovirus could be considered an important viral etiological agent for acute gastroenteritis among children in northeast India along with other etiology.

Key Words: Acute Gastroenteritis, Adenovirus, Diarrhea, Northeast India, Prevalence.

\section{${ }^{*}$ Correspondence to:}

Aniruddha Jakharia,

Regional Medical Research Centre for NE Region (ICMR), Dibrugarh, India.

Email: ajakharia@gmail.com

\section{Article History:}

Received: 23-08-2016, Revised: 28-08-2016, Accepted: 30-08-2016

\begin{tabular}{|l|c|}
\hline \multicolumn{2}{|c|}{ Access this article online } \\
\hline Website: & Quick Response code \\
www.jmm.com & \\
\hline DOl: & \\
10.21276/jmrp.2016.2.5.025 & \\
\hline
\end{tabular}

identified and grouped into seven species $A$ to $G$ on the basis of haemagglutination, serum neutralization and genome analysis. ${ }^{10,11}$ The disease pattern of adenovirus varies species to species. Adenovirus species $F$ mainly type 40 and 41 are found to be regularly associated with gastroenteritis and are grouped in enteric adenovirus. ${ }^{12}$ It accounts for $20 \%$ of the diarrheal diseases globally especially in children below five years. Other species such as $A, C$, and $D$ have also been associated with diarrhea. ${ }^{13}$ Accurate understanding of the relative prevalence of enteric adenovirus in hospitalized diarrheal cases is important for effective management and preventive measures. In North East India, diarrheal diseases caused by viral etiologies have not been studied thoroughly and currently no data are available regarding the specific contribution of enteric adenovirus among children diarrhea. To address these knowledge gaps, the present study 
was undertaken to determine the relative prevalence and characterization of enteric adenovirus infection among hospitalized children aged 0-59 months with diarrhea in Dibrugarh, Assam, Northeast India. Furthermore, the seasonality of enteric adenovirus infection from this region of India was also investigated.

\section{MATERIALS AND METHODS}

\section{Sample Collection}

Samples were collected from a tertiary hospital of Northeast India, Assam Medical College and Hospital, (AMCH) Dibrugarh, Assam for screening of rotavirus antigen $(\mathrm{Ag})$ under the study National hospital based rotavirus surveillance network. A total of 455 fecal specimens were collected from children aged below 5 years who were hospitalized for diarrhea during the period from May 2013 to April 2015. A total of 238 cases negative for rotavirus diarrhea during the period were screened for enteric adenovirus Ag. The inclusion criteria of the cases were hospitalized children aged $<5$ years with acute watery diarrhea, with or without vomiting and abdominal pain. Written informed consent was taken from either the guardian/parents of the patient participating in the study in a protocol approved by the Institutional Ethical Committee of Regional Medical Research Centre (RMRC) for Northeast Region, Indian council of medical research (ICMR).

\section{Enteric Adenovirus Ag Detection}

Preliminary screening of the rotavirus negative fecal samples for the detection of enteric adenovirus $\mathrm{Ag}$ was performed using Adenovirus Ag ELISA kit (DRG Instruments $\mathrm{GmbH}$, Germany) in accordance with the manufacturer's instructions.

\section{Viral DNA Extraction}

For viral DNA extraction, 30\% (v/v) suspensions of adenovirus Ag positive stool samples were prepared in sterile Dulbecco's Modified Eagle Medium (DMEM) - low glucose (Sigma, MO, USA) by addition of $1.5 \mathrm{~g}$ of semi-solid faces or approximately $1.5 \mathrm{ml}$ of liquid feces in $3.5 \mathrm{ml}$ of DMEM. The suspension was vortex thoroughly for $1 \mathrm{~min}$ and centrifuged at 10,000 rpm for $10 \mathrm{~min}$ at $4^{\circ} \mathrm{C}$. The clarified supernatant was collected carefully and stored in aliquots at $-20^{\circ} \mathrm{C}$ until further processing. For molecular typing, every enteric adenovirus $\mathrm{Ag}$ positive supernatant was used for viral DNA extraction by QIAamp DNA Mini Kit (Qiagen, Hilden, Germany), according to manufacturer's instructions.

\section{Enteric Adenovirus Detection by PCR for Hexon and Fiber} Genes

PCR was carried out in $50 \mu$ reaction mix containing $5 \mu$ of viral DNA template, $25 \mu \mathrm{l}$ of $2 \mathrm{X}$ PCR master mix (Promega, USA), $1 \mathrm{\mu l}$ each of adenovirus hexon gene primers (20 pmol $/ \mathrm{ml})$ Ad1-5'-TTCCCCATGGCICAYAACAC-5', Ad2-5'CCCTGGTAKCCRATRTTGTA-5'and fiber gene $F$ specific primers (20 pmol/ml) AdF1-5'-ACTTAATGCTGACACGGGCAC-3' and AdF2-5'-TAATGTTTGTGTTACTCCGCTC-3'. ${ }^{14}$ The volume was made up to $50 \mu \mathrm{l}$ with distilled water. Thermal profile consisted of an initial denaturation step at $94^{\circ} \mathrm{C}$ for $5 \mathrm{~min}$ followed by 30 cycles at $94{ }^{\circ} \mathrm{C}$ for $1 \mathrm{~min}, 54{ }^{\circ} \mathrm{C}$ for $45 \mathrm{sec}, 72^{\circ} \mathrm{C}$ for $2 \mathrm{~min}$ with final extension at $72^{\circ} \mathrm{C}$ for $7 \mathrm{~min}$ for both hexon and fiber gene regions. PCR products were loaded on to $1.5 \%$ agarose gel containing ethidium bromide $(0.01 \mathrm{mg} / \mathrm{ml})$ along with $100 \mathrm{bp}$ molecular size ladder and viewed in a gel-documentation system.

The PCR products were purified using High pure PCR product purification kit (Roche, Mannheim, Germany). Purified PCR products were sequenced using dideoxy cycle sequencing (Sanger) reaction in both directions in a 3130 Genetic Analyzer (PE Applied Biosystems, Hitachi, Japan).

\section{Nucleotide Sequence Accession Numbers}

Accession numbers of the adenovirus hexon gene and fiber gene sequences submitted to GeneBank are: KU904307 to KU904313 and KU681045 to KU681056 respectively.

\section{Phylogenetic Analysis}

Nucleotide sequence BLAST search was performed using the National Centre for biotechnology Information (NCBI, National Institutes of Health, Bethesda, MD) Basic Local Alignment Search Tool (BLAST) server on GenBank database release 143.0. ${ }^{15}$

Adenovirus hexon gene and shaft region of fiber gene sequences were aligned separately using Clustal W (codons) application in Molecular Evolutionary Genetics Analysis (MEGA) version 7.0.16 Moreover, model selection of the aligned sequences was also performed in MEGA 7.0. As per the best-fit model the evolutionary history was inferred using Maximum Likelihood method based on Tamura 3-parameter model for hexon gene and HasegawaKishino-Yano modelfor fiber shaft region. ${ }^{17,18}$

Adeno virus hexon gene and shaft region of fiber gene analysis involved 20 and 23 nucleotide sequences of which 7 and 12 sequences are of the present study respectively, while rest are most nearest respective related sequences and reference/prototype sequences from GenBank.

\section{Statistical Analysis}

Standardized questionnaires for diarrheic cases, enteric Adenovirus Ag ELISA and sequencing result reports were used to generate data for statistical analysis. Statistical analysis was performed using Statistical Package for the Social Sciences (SPSS) version 20.0 (trial version). Differences in proportions of enteric adenovirus positivity in different age, sex, season and genotype were tested using the Pearson Chi-square $\left(X^{2}\right)$ test. Odds ratio and their $95 \%$ confidence interval $(\mathrm{Cl})$ were calculated to measure the magnitude and direction of association. A cut off $P$-value of $<0.05$ was considered significant.

\section{RESULTS}

\section{Burden and Demographic Characteristics}

The demographic characteristics of the enrolled children in the present surveillance have been summarized in table 1. Among 238 screened fecal samples, 26 (10.9\%; Cl: 6.9 to 14.8) samples were Adenovirus $\mathrm{Ag}$ ELISA positive which showed 100\% concordance with PCR test. The age distribution among children suffering from adenovirus infection is shown in table 1 . High incidence of adenovirus infection was observed among $\leq 12$ months of age $(16.3 \%)$ as compared to the other age groups $(P=0.17)$. Table 1 shows frequency of enteric adenovirus infection was higher in females $(15.1 \%)$ compared to males $(8.3 \%)$ however statistically not significant $(p=0.1)$. Enteric adenovirus infection is highest in the children with severe dehydration (33\%),followed by children with some dehydration (11.2\%) and none of the children have enteric adenovirus infection without any dehydration(Table 1).Adenovirus prevalence was higher (14.9\%) in children with episodes of diarrhea $\geq 10$ times compared to children with $\leq 9$ times $(P=0.047)$. Moreover, restlessness $(50 \%)$ among the enteric adenovirus infected children are significantly higher $(P=0.002)$. Other baseline characteristics including clinical presentations are shown in table 1. 
Table 1: Demographic/clinical characteristics of the children enrolled in the present study.

\begin{tabular}{|c|c|c|c|c|c|c|}
\hline \multicolumn{2}{|c|}{$\begin{array}{l}\text { Demographic and clinical } \\
\text { characteristic }\end{array}$} & \multirow{2}{*}{$\begin{array}{c}\begin{array}{c}\text { Total enrolled } \\
\text { cases } \mathrm{N}=238\end{array} \\
145\end{array}$} & \multirow{2}{*}{$\begin{array}{c}\begin{array}{c}\text { Enteric Adenovirus } \\
\text { positive } \mathbf{N}=\mathbf{2 6}\end{array} \\
12(8.3 \%)\end{array}$} & \multirow{2}{*}{$\begin{array}{c}P \text { value } \\
0.1\end{array}$} & \multirow[t]{2}{*}{ OR } & \multirow[t]{2}{*}{$\mathrm{Cl} 95 \%$} \\
\hline Sex & Male & & & & & \\
\hline & Female & 93 & $14(15.1 \%)$ & & 1.9 & $0.86-4.4$ \\
\hline Age in & $0-12$ & 49 & $8(16.3 \%)$ & 0.17 & \multicolumn{2}{|c|}{1.0 (ref). } \\
\hline \multirow[t]{2}{*}{ months } & $13-24$ & 76 & $6(7.9 \%)$ & & 0.43 & $0.14-1.3$ \\
\hline & $\geq 25$ & 113 & $12(10.6 \%)$ & & 0.6 & $0.23-1.6$ \\
\hline \multirow[t]{4}{*}{ Diarrhea } & $\leq 3$ days (duration) & 121 & $11(9.1 \%)$ & 0.35 & \multicolumn{2}{|c|}{1.0 (ref) } \\
\hline & $\geq 4$ days (duration) & 117 & $15(12.8 \%)$ & & 1.5 & 0.64 to 3.3 \\
\hline & $\leq 9$ times (episodes) & 117 & $8(6.8 \%)$ & 0.047 & \multicolumn{2}{|c|}{1.0 (ref) } \\
\hline & $\geq 10$ times(episodes) & 121 & $18(14.9 \%)$ & & 2.4 & $1.01-5.7$ \\
\hline \multirow[t]{5}{*}{ Vomiting } & No vomiting & 66 & $7(10.6 \%)$ & 0.27 & \multicolumn{2}{|c|}{1.0 (ref) } \\
\hline & $\leq 2$ days (duration) & 126 & $11(8.7 \%)$ & & 0.8 & 0.3 to 2.2 \\
\hline & $\geq 3$ days (duration) & 46 & $8(17.4 \%)$ & & 1.8 & 0.6 to 5.3 \\
\hline & $\leq 3$ times (episodes) & 90 & $9(10 \%)$ & 0.9 & 0.9 & 0.33 to 2.6 \\
\hline & $\geq 4$ times (episodes) & 83 & $10(12 \%)$ & & 1.15 & 0.41 to 3.2 \\
\hline \multirow[t]{3}{*}{ Hydration } & No dehydration & 11 & $0(0 \%)$ & 0.23 & - & - \\
\hline & Some dehydration & 124 & $25(11.2 \%)$ & & \multicolumn{2}{|c|}{1.0 (ref) } \\
\hline & Severe dehydration & 3 & $1(33.3 \%)$ & & 2.0 & 0.2 to 22.7 \\
\hline \multicolumn{2}{|c|}{ No lethargy } & 120 & $11(9.2 \%)$ & 0.38 & \multicolumn{2}{|c|}{1.0 (ref) } \\
\hline \multicolumn{2}{|l|}{ Lethargy } & 118 & $15(12.7 \%)$ & & 1.4 & 0.6 to 3.3 \\
\hline \multicolumn{2}{|c|}{ No restlessness } & 232 & $23(9.9 \%)$ & 0.002 & \multicolumn{2}{|c|}{1.0 (ref) } \\
\hline \multicolumn{2}{|c|}{ Restlessness } & 6 & $3(50 \%)$ & & 9.1 & 1.7 to 47.6 \\
\hline \multicolumn{2}{|c|}{ Feeding well } & 125 & $11(8.8 \%)$ & 0.27 & \multicolumn{2}{|c|}{1.0 (ref) } \\
\hline \multicolumn{2}{|c|}{ Not feeding well } & 113 & $15(13.3 \%)$ & & 1.6 & 0.7 to 3.6 \\
\hline \multicolumn{2}{|c|}{ Temperature ${ }^{*}>37^{\circ} \mathrm{C}$} & 125 & $12(9.6 \%)$ & 0.58 & \multicolumn{2}{|c|}{1.0 (ref) } \\
\hline \multicolumn{2}{|c|}{ Temperature $^{*} \leq 37^{\circ} \mathrm{C}$} & 110 & $13(11.8 \%)$ & & 1.3 & 0.55 to 2.9 \\
\hline
\end{tabular}

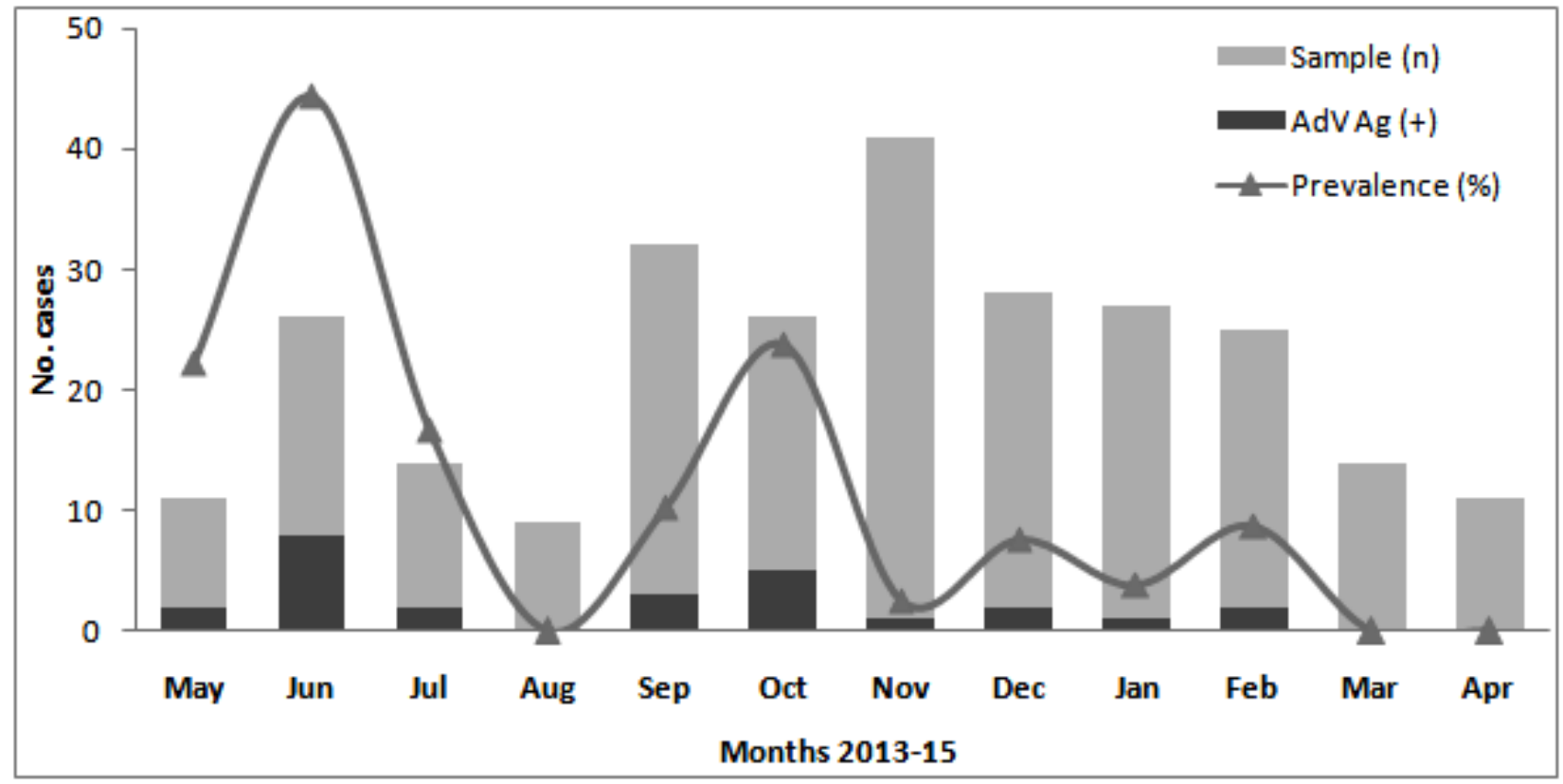

Fig 1: Epidemic curve shows prevalence of enteric adenovirus infection in children hospitalised for AGE in AMCH, Dibrugarh, Northeast India during 2013-15.

\section{Infection Seasonality}

To determine the role of seasonal changes in the prevalence of enteric adenovirus, data was analyzed on a monthly basis for 2 years (2013-2015). Prevalence of enteric adenovirus infection was higher during May to July and in the month of October, though sporadic cases wereobserved throughout the year (Fig 1).
Additionally, the months of the study were divided into the season of the year i.e. warmer months (April through September) and cooler months (October through March). Frequency of enteric adenovirus infection was higher during warmer months $(17 \%)$ than cooler months $(7.3 \%)(P=0.0001)$. 


\section{Phylogenetic Analysis}

Molecular evolutionary analysis on the hexon gene showed type 41 to be the prevalent genotype in the study population. Type 40 was detected in only one sample. The hexon gene type 41 sequences from the study region created a single genomic type cluster in the population (Fig 2). All the six (type 41) sequences had a very high degree $(100 \%)$ of similarity with those of the Thailand (KC632630) and South Korea (HQ326162) rather than from other sequences available from rest of India. The only hexon gene type 40 sequence from the present study had very high degree $(100 \%)$ of similarity with the available sequences from Thailand (Fig 2). The average mean distance of hexon gene from the study region (Dibrugarh) for type 41 strains is $0.1 \%$; between Dibrugarh type 41 and 40 strains is $13.2 \%$; between Dibrugarh type $41 / 40$ and rest of the strain is $0.7 \% / 0.4 \%$; between Dibrugarh type $41 / 40$ and out group is $24.8 \% \& 25.6 \%$ respectively.
Molecular evolutionary analysis based on the nucleotide sequences of the shaft region of the fiber gene revealed presence of two sub-lineages (DIB-1 and DIB-2) in the study population (Fig 2). Out of 12 sequences from the present study, five each clustered into the DIB-1 and DIB-2. Two sequences does not cluster into any of the two sub lineages and the sequences had a very high degree of similarity with those of the two Kolkata strains (HQ010343, HQ010350) (Fig 2). The average mean distance of shaft region of fiber gene within the Dibrugarh type 41 strains is $0.3 \%$; between Dibrugarh type 41 and prototype TAK strain (X16583) is $1.8 \%$; between Dibrugarh type 41 DIB-1 and DIB-2 strain is $0.5 \%$; between Dibrugarh type 41 DIB-1/DIB-2 and distance between the two strains which did not fall in any of the two sub lineages is $0.3 \%$. For the fiber gene the average mean distance between the Dibrugarh type 41 and type 40 is $8 \%$.

\section{a}

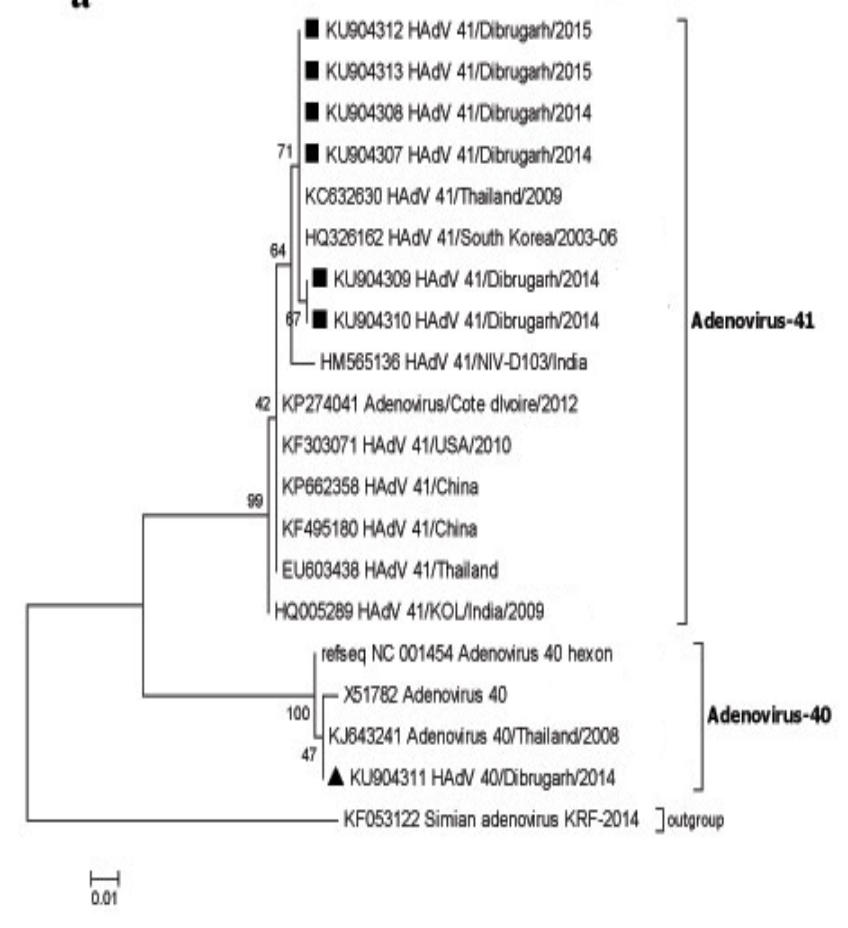

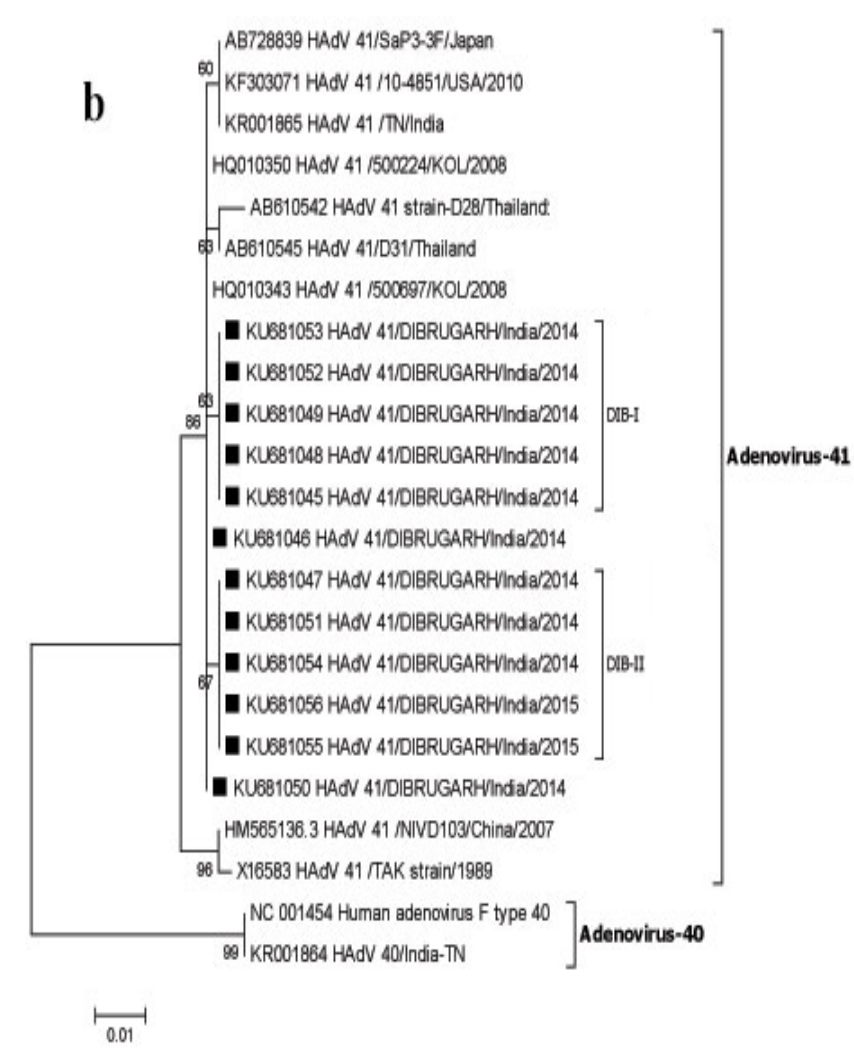

Fig 2: Phylogenetic tree based on the nucleotide sequence of the hexon gene (a) and the shaft region of the fiber gene (b) of representative adenovirus strains from children in Assam, northeast India, during May 2013 through April 2015.

The phylogenetic trees were constructed by the neighbor-joining method with 1,000 bootstrap replications in the

Clustal W program. The numbers at internal nodes indicate the bootstrap values. The designations indicate the strain accesion no./type/place of origine/year of infection for the strains detected in this study. DIB-I and DIB-II denote sub-leneage clusters in the fiber gene. For the hexon gene (a) and the shaft region of the fiber gene (b) respective 13 and 11 nearest respective related sequences and reference/prototype sequences from GenBank. Simian adenovirus (KF053122) strain is used as outgroup for hexon gene analysis.

\section{Deduced Amino Acid Analysis}

In the present study, clustalW analysis of all the deduced amino acid of the adenovirus shaft region of fiber gene sequences from Dibrugarh showed 15 amino acid deletions against the prototype TAK strain (Fig 3). This deletion of the 15 amino acids was confined to $15^{\text {th }}$ repeat motif in the fiber gene shaft region. Additionally, two substitutions were also observed in the $199^{\text {th }}$ and $250^{\text {th }}$ position i.e. serine $(\mathrm{S})$ is substituted by asparagine $(\mathrm{N})$ and valine $(\mathrm{V})$ is substituted by phenylalanine (Fig 3) Among the 15 partial adenovirus- 41 hexon protein strains analyzed, there was no dissimilarity observed at the amino acid sequences. Similarly, no mutation was observed at the amino acid sequences of the partial adenovirus-40 hexon protein also. 


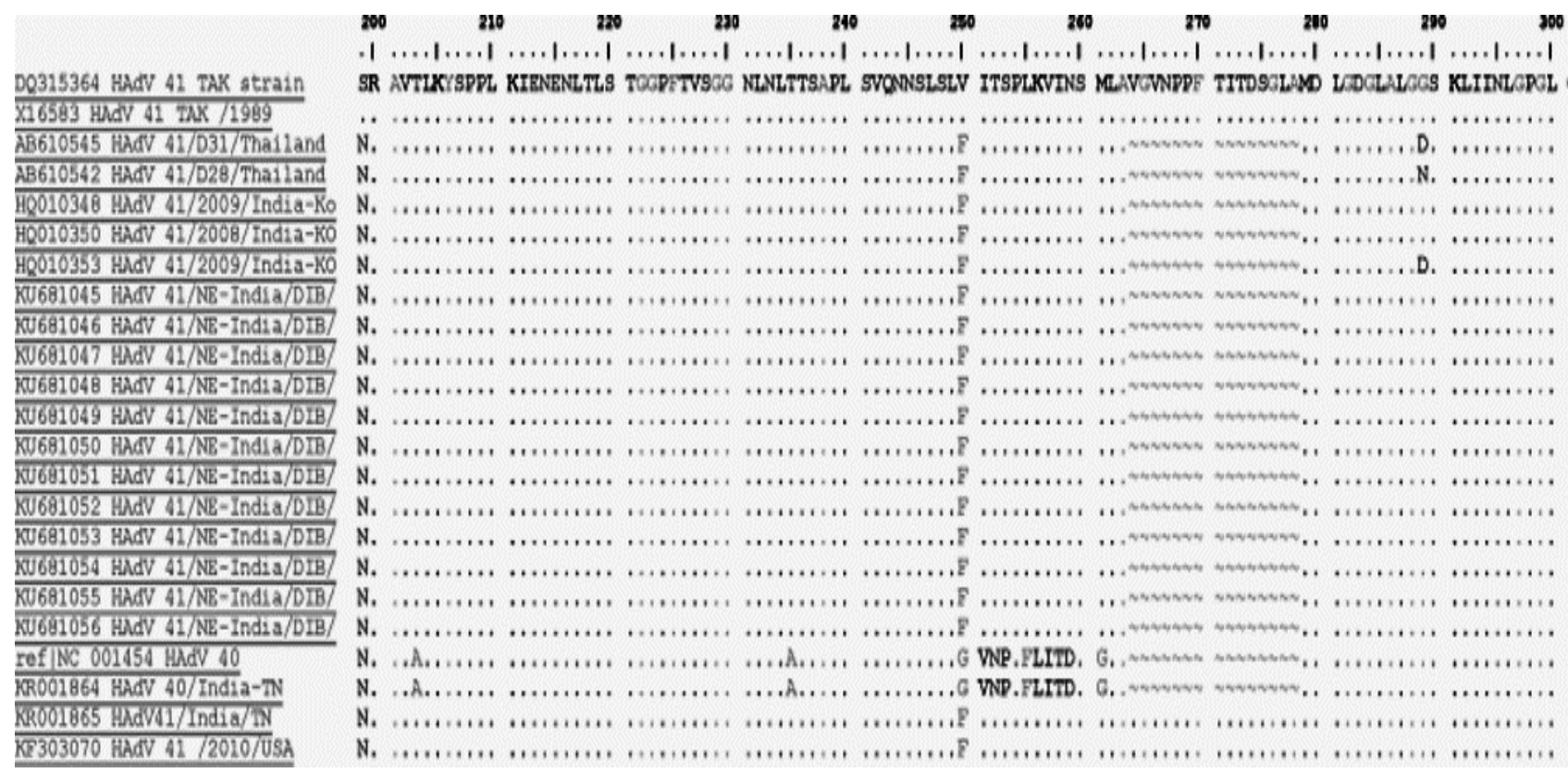

Fig 3: Alignment of the deduced amino acid sequences of the shaft region of fiber gene from 12 adenovirus type 41 strains from the present study.

\section{DISCUSSION}

Viral gastroenteritis is one of the major health problems that cause considerable disease burden in both developed and developing countries. ${ }^{19}$ Even though rotavirus is the major viral pathogen responsible for AGE, however enteric adenovirus has been reported to cause sporadic infections and outbreaks of gastroenteritis. $8,20,21$ The molecular epidemiology of enteric adenovirus species from northeast India is described for the first time in the present study. The study highlights the prevalence and seasonality of enteric adenovirus among the hospitalized children with AGE in Dibrugarh, Assam.

Epidemiological studies of enteric adenovirus in infants and children with AGE have shown its importance in other parts of India as well as globally. Prevalence of enteric adenovirus reported from western India, Pune, Aurangabad, and Nagpur showed respectively $9 \%, 7 \%$, and $7.5 \%$ and from eastern India, Kolkata showed $6.5 \% .22,23$ Enteric adenovirus prevalence reported from other parts of the world, Alabania, China, Japan, Iran, Bangladesh and Tanzania showed 9.8\%, 9.8\%, 8\%, 6.5\%, $2.8 \%$ and $1.8 \%$ respectively. $8,11,24-27$

Enteric adenovirus diarrhea was prevalent sporadically during the study period 2013-15 and concurred with the recent reports from rest of India.22,23 In the current study the enteric adenovirus prevalence $(10.9 \%)$ in diarrheal stool specimens from Dibrugarh was much higher than that previously reported from other Indian regions as well as other parts of the world. ${ }^{22,23}$ These findings revealed the implication of enteric adenovirus burden in this region. Globally, the patterns of diarrheal etiology are changing, with viral pathogens becoming more frequent. ${ }^{28}$ This may be rather due to improved diagnosis for viral pathogens in recent years. Moreover, in the present investigation it was observed that adenovirus is more prevalent during warmer months contrary to rotavirus diarrhea which is more prevalent in the cooler months also known as winter diarrhea, so we may call adenovirus diarrhea as summer diarrhea.

It has been generally thought that enteric diarrhea caused by adenovirus is milder than rotavirus diarrhea. ${ }^{29}$ However, clinical features described here showed severe diarrhea, ( $\geq 10$ times) and restlessness is significantly higher in enteric adenovirus infected children. Moreover, enteric adenovirus infection in children $<12$ months and females is higher compared to children $>12$ months and males respectively. Of the clinical features that were examined, among the adenovirus infected children (26/238) frequency of dehydration (100\%), lethargy $(58 \%)$ and not feeding well $(58 \%)$ are alarmingly higher. These findings reveal that enteric adenovirus can also cause severity similar to rotavirus.

The hexon gene and shaft region of fiber genes are considered prone site for base mutations and recombination, which were responsible for adenovirus serotype evolution. ${ }^{30-33}$ The hexon protein and fiber protein collectively enables the virus to attach to the cellular receptor and plays important role for the serotype specificity of adenovirus strains. Genotyping was done for both the hyper variable regions of the hexon gene and shaft region of fiber gene, so that genetic variation between the strains does not get overlooked. ${ }^{34}$ In general, the fiber gene exhibited greater genetic variability than the hexon gene. The phylogenetic analysis confirms, the hexon gene clustered into one lineage; and the fiber gene clustered into two sub lineages DIB-1 and DIB-2.

Amino acid sequences analysis of the fiber adenovirus 41 gene from the present study, showed deletion of 15 amino acids. There were 22 and 21 repeat motifs in the shaft region of the adenovirus-41 and adenovirus-40 fiber polypeptide respectively. The coding region of the shaft region was intact, as the entire 15 aminoacid coding region from both adenovirus-40/41 had been excised from the sequence. This deletion of the $15^{\text {th }}$ repeat motif from the circulating adenovirus- 41 strains reduced the sequence size of fiber gene, and became same size as the fiber adenovirus40 gene. It seems that adenovirus-40 and this adenovirus- 41 strain circulating in Assam, northeast India, apply similar mechanism to interact with the host receptor. In the circulating strains from Dibrugarh, this deletion of 15 amino acids is evolutionarily conserved. This diversity of AdV- 41 has been reported earlier also, from where strains $A B 610545$ 
Adenovirus41/D31/Thailand, HQ010348 Adenovirus41/2009/IndiaKolkata, Ad41/D6/17951/Netherlandsand Ad41/D8/N7761/Canada had similar deletions. However, the gene sequences from Netherlands and Canada are not available in GenBank for amino acid sequences analysis against the enteric adenovirus strains from Dibrugarh. The shaft region of fiber has a triple $\beta$-spiral motif which is stable yet flexible. It has been speculated that a shortened fiber gene size may facilitate rapid replication and/or may have association with pathogenicity; however no concrete evidence has been reported yet. ${ }^{35}$

In conclusion, the present investigation reveals existence of enteric adenovirus-40/41 strain in hospitalized children with AGE and is an important pathogen in causing AGE among children aged below 5 years in northeast India. This is the first report on molecular characterization of enteric adenovirus-40/41 strains, revealing the presence of unique 15 amino acids deletion in the shaft region of the fiber gene from this region, similar to the study conducted at Kolkata, eastern India. ${ }^{23}$ Moreover, for the first time investigation of the seasonality of enteric adenovirus infection from this region, revealed sporadic incidences throughout the year and comparatively higher incidences in the month of May to July and October.

\section{ACKNOWLEDGEMENT}

The present investigation was supported by Department of Health and Research, Ministry of Health and Family Welfare, Govt. of India. Under the scheme "Establishment of a network of Laboratories for Managing Epidemics and Natural Calamities".

\section{SOURCE OF SUPPORT}

Department of Health and Research, Ministry of Health and Family Welfare, Govt. of India. Under the scheme "Establishment of a network of Laboratories for Managing Epidemics and Natural Calamities".

\section{REFERENCES}

1. Lekana-Douki SE, Kombila-Koumavor C, Nkoghe D, Drosten C, Drexler JF, Leroy EM. Molecular epidemiology of enteric viruses and genotyping of rotavirus $A$, adenovirus and astrovirus among children under 5 years old in Gabon. Int $\mathrm{J}$ Infect Dis: Official publication of the International Society for Infectious Diseases 2015; 34:90-95.

2. Borrows $\mathrm{CL}$, Turner PC. Seasonal screening for viral gastroenteritis in young children and elderly hospitalized patients: is it worthwhile? J. Hosp. Infect 2014; 87(2):98-102.

3. Amaral MS, Estevam GK, Penatti M, et al. The prevalence of norovirus, astrovirus and adenovirus infections among hospitalised children with acute gastroenteritis in Porto Velho, state of Rondonia, western Brazilian Amazon. Mem Inst Oswaldo Cruz 2015; Rio de Janeiro, Vol. 110(2): 215-221.

4. Parashar UD, Gentseh JR, Glass RI. Rotavirus. Emerg Infect Dis 1998; 4:561-570.

5. Chen SY, Chang YC, Lee YS, et al. Molecular epidemiology and clinical manifestations of viral gastroenteritis in hospitalized pediatric patients in Northern Taiwan. J. Clin. Microbiol 2007; 45(6):2054-2057.

6. Filho EP, da Costa Faria NR, Fialho AM, et al. Adenoviruses associated with acute gastroenteritis in hospitalized and community children up to 5 years old in Rio de Janeiro and Salvador, Brazil. J Med Microbiol 2007; 56(3): 313-319.

7. Harsi CM, Rolim DP, Gomes SA, et al. Adenovirus genome types isolated from stools of children with gastroenteritis in Sao Paulo, Brazil. J Med Virol 1995; 45(2):127-134.

8. Shimizu H, Phan TG, Nishimura S, Okitsu S, Manee N, Ushijome $\mathrm{H}$. An outbreak of adenovirus serotype 41 infection in infantsand children with acute gastroenteritis in Maizura City, Japan. Infect Genet Evol 2007; 7:279-284.

9. Sandkovsky U, Vargas L, Florescu DF. Adenovirus: current epidemiology and emerging approaches to prevention and treatment. Current infectious disease reports 2014; 16(8):416.

10. La Rosa G, Della Libera S, Petricca S, et al. Genetic Diversity of Human Adenovirus in Children with Acute Gastroenteritis, Albania, 2013-2015. Bio Med Res. Int 2015:142912.

11. Moyo SJ, Hanevik K, Blomberg B, et al. Prevalence and molecular characterisation of human adenovirus in diarrhoeic children in Tanzania; a case control study. BMC Infect Dis 2014; 14:666.

12. Kuhn JH, Radoshitzky SR, Bavari S, Jahrling PB. The International Code of Virus Classification and Nomenclature (ICVCN): proposal for text changes for improved differentiation of viral taxa and viruses. Arch Virol 2013; 158(7):1621-1629.

13. Lu L, Jia R, Zhong $H$, et al. Molecular characterization and multiple infections of rotavirus, norovirus, sapovirus, astrovirus and adenovirus in outpatients with sporadic gastroenteritis in Shanghai, China, 2010-2011. Arch Virol 2015; 160(5):1229-1238. 14. Xu WH, McDonough MC, Erdman DD. Species-Specific Identification of Human Adenoviruses by a Multiplex PCR Assay. J. Clin. Microbiol 2000; 38(11); 4114-4120.

15. Schaffer AA, Aravind L, Madden TL, et al. Improving the accuracy of PSI-BLAST protein database searches with composition-based statistics and other refinements. Nucleic Acids Res 2001; 29:2994-3005.

16. Kumar S, Stecher G, Tamura K. MEGA7: Molecular Evolutionary Genetics Analysis version 7.0 for bigger datasets. Molecular Biology and Evolution. Mol Biol Evol2016; 33(7):1870-4. 17. Nei M, Kumar S. Molecular Evolution and Phylogenetics. Oxford University Press, New York 2000; (p333).

18. Hasegawa M, Kishino H, Yano T. Dating the human-ape split by a molecular clock of mitochondrial DNA. J Mol Evol 1985; 22:160-174.

19. Murray CJ, Lopez AD. Mortality by cause for eight regions of the world; Global Burden of Disease study. Lancet 1997; 349:1269-1276.

20. Kotloff KL, Nataro JP, Blackwelder WC, et al. Burden and aetiology of diarrhoeal disease in infants and young children in developing countries (the Global Enteric Multicenter Study, GEMS): a prospective, case-control study. Lancet 2013; 382:20922.

21. Akihara S, Phan TG, Nguyen TA, Hansman G, Okitsu S, Ushijima $\mathrm{H}$. Existence of multiple outbreaks of viral gastroenteritis among infants in a day care center in Japan. Arch Virol 2005; 150:2061-2075.

22. Verma H, Chitambar SD, Varanasi G. Identification and Characterization of Enteric Adenoviruses in Infants and Children Hospitalized for Acute Gastroenteritis. J Med Virol 2009; 81 : 60-64. 
23. Dey RS, Ghosh S, Sarkar MC, et al. Circulation of a Novel Pattern of Infections by Enteric Adenovirus Serotype 41 among Children below 5 Years of Age in Kolkata. Ind $\mathrm{J}$ Clin Microbiol 2011; 49(2):500-505.

24. Fabiana A, Donia D, Gabrieli R, et al. Influence of enteric viruses on gastroenteritis in Albania: epidemiological and molecular analysis. J Med Virol 2007; 79(12): 1844-1849.

25. Liu L, Qian Y, Zhang Y, Deng J, Jia L, Dong H. Adenoviruses Associated with Acute Diarrhea in Children in Beijing, China. PLoS ONE 2014; 9(2): e88791.

26. Dashti AS, Ghahremani $P$, Hashempoor T, Karimi A. Molecular Epidemiology of Enteric Adenovirus Gastroenteritis in under-Five-Year-Old Children in Iran. Gastroenterol Res Pract 2016; Volume 2016, Article ID 2045697, 5 pages.

27. Khan KJ, Tzipori SR, Unicomb LE. Enteric Adenovirus Infection among Infants with Diarrhea in Rural Bangladesh. J Clin Microbiol 1993; 484-489.

28. Kang G, Arora R, Chitambar SD, et al. Multicenter, HospitalBased Surveillance of Rotavirus Disease and Strains among Indian Children Aged <5 Years. J Infect Dis 2009; 200: S147153.

29. Wadell G, Allard A, Johansson M, Svensson L, Uhnoo I. Enteric adenoviruses. CIBA Found Symp 1987; 128:63-91.

30. Darr S, Madisch I, Hofmayer S, Rehren F, Heim A. Phylogeny and primary structure analysis of fiber shafts of all human adenovirus types for rational design of adenoviral gene-therapy vectors. J Gen Virol 2009; 90, 2849-2854.

31. Kajon AE, Dickson LM, Murtagh P, Viale D, Carballal G, Echavarria M. Molecular characterization of an adenovirus $3-16$ inter typic recombinant isolated in Argentina from an infant hospitalized with acute respiratory infection. J Clin Microbiol 2010; 48, 1494-1496.

32. Lukashev AN, Ivanova OE, Eremeeva TP, Iggo RD. Evidence of frequent recombination among human adenoviruses. J Gen Virol 2008; 89, 380-388.

33. Yang Z, Zhu Z, Tang L, et al. Genomic analyses of recombinant adenovirus 11a in China. J Clin Microbiol 2009; 47, 3082-3090.

34. Gray GC, McCarthy T, Lebeck MG, et al. Genotype prevalence and risk factors for severe clinical adenovirus infection, United States 2004-2006. Clin Infect Dis 2007; 45: 1120-1131.

35. Kidd AH, Erasmus MJ, Tiemessen CT. Fiber sequence heterogeneity in subgroup $\mathrm{F}$ adenoviruses. Virology 1990; 179:139-150.

\section{Conflict of Interest: None Declared.}

Copyright: (c) the author(s) and publisher. IJMRP is an official publication of Ibn Sina Academy of Medieval Medicine \& Sciences, registered in 2001 under Indian Trusts Act, 1882.

This is an open access article distributed under the terms of the Creative Commons Attribution Non-commercial License, which permits unrestricted non-commercial use, distribution, and reproduction in any medium, provided the original work is properly cited.

Cite this article as: Biswajyoti Borkakoty, Aniruddha Jakharia, Chandrakanta Bhattacharya, Mandakini Das, Dipankar Biswas, Jagadish Mahanta. Prevalence of Enteric Adenovirus among NonRotavirus Diarrhea in Assam, Northeast India. Int J Med Res Prof. 2016; 2(5):124-30. 